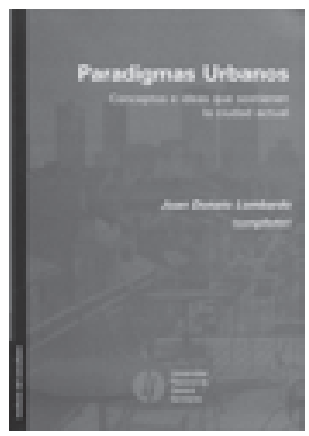

\title{
Juan Donato Lombardo (compilador). Paradigmas urbanos. Conceptos e ideas que sostienen la ciudad actual
}

\author{
Buenos Aires: Universidad Nacional General Sarmiento, \\ 2007, 145 p.
}

\author{
Vanina Inés Caamaño ${ }^{1}$
}

Este libro, que aborda los paradigmas en el marco del proceso de construcción de la ciudad, es producto de un seminario internacional que han organizado conjuntamente el Instituto de Conurbano de la Universidad Nacional General Sarmiento y la Asociación Latinoamericana de Escuelas de Urbanismo y Planeación. Dicho seminario estuvo a cargo de los miembros del equipo que trabaja en el Instituto del Conurbano sobre el tema "Construcción del espacio urbano en la Región Metropolitana de Buenos Aires (RMBA)".

En esta obra se plantea la cuestión de los paradigmas en el marco de las relaciones que se establecen entre los distintos instrumentos y procesos urbanos, y las consecuentes transformaciones que implican la acción de los llamados procesos de reestructuración global que tienen lugar en todas las áreas de la sociedad.

La exploración de este tema se sitúa en el contexto de las transformaciones que se están produciendo, ya sean de carácter social y/o espacial y con la relativa incertidumbre que aun presentan los análisis. El tema de la consideración del espacio como construcción social dio lugar a un debate para tratar de centrar la cuestión.

1 Estudiante del Profesorado y Licenciatura en Geografía. Becaria de Investigación de la Secretaría General de Ciencia y Técnica de la Universidad Nacional del Nordeste (Argentina). E-mail: vaica84@yahoo.com.ar
El título Paradigmas urbanos es, en sí mismo, una presentación epistemológica del contenido. Remite al concepto semántico de paradigma que Thomas Khun definió en términos de supuestos teóricos generales, leyes y técnicas para su aplicación que una determinada sociedad adopta en un periodo de tiempo concreto, es decir, conceptos o categorías maestras de la inteligibilidad que los individuos conocen, piensan y actúan según los paradigmas inscritos culturalmente en ellos.

Sobre estos planteamientos preliminares, el compilador ha reunido siete trabajos que, a través de los paradigmas, intentan introducir al lector en el debate mantenido entre investigadores de diferentes escuelas de urbanismo latinoamericanas sobre la cuestión de la construcción de la ciudad.

La obra se estructura en dos partes. La primera contiene la introducción, en la cual el compilador realiza la presentación del tema, orientando las ideas preliminares y el enfoque teórico en el cual se inserta este libro. La segunda parte contiene los siete trabajos presentados en el seminario, los que permiten incluir aquellos temas que ayudan a comprender las transformaciones en las relaciones que sostienen la idea de construcción del espacio. Los trabajos se presentan de una forma muy clara y didáctica, de tal manera que logran sistematizar en pocas líneas la dirección histórica del tema y el estado actual de discusión.

En el primer apartado, titulado Las actuales transformaciones de los paradigmas urbanos, el Dr. López Rancel se centra en la 
construcción de conceptos e ideas y los cambios operados en el tiempo.

En el segundo apartado, Los paradigmas subyacentes en los estudios urbanos, el Dr. Rodríguez analiza lo urbano y los paradigmas que subyacen a las disciplinas que lo estudian.

El tercer capítulo, que lleva por nombre La totalidad y la ceguera. Fundamentos para una crítica de los paradigmas de análisis de la ciudad y del fenómeno de la urbanización actual, es el trabajo presentado por Elizette Menegat, quien se refiere a los conceptos e ideas que sostienen la construcción social del espacio.

En el cuarto apartado, Un viejo paradigma urbano: la calle como lugar de encuentro cara a cara, la profesora Flores tiene por objetivo mostrar que el interés de la calle es de antaño, analizando cada uno de los conceptos que componen dicho paradigma a través del tiempo.

En la quinta sección, Mundialización de los mercados, economía urbana y configuración territorial de la Región Metropolitana de Buenos Aires, Sabaté trata sobre los paradigmas económicos en la sociedad y sus transformaciones actuales.

El sexto capítulo, La gestión de la infraestructura urbana: un paradigma en construcción, se debate el concepto de paradigma en el ámbito de la infraestructura urbana.
Finalmente, en la séptima y última sección, la Dra. Quintar presenta algunas $R e$ flexiones en torno al fenómeno de las asambleas barriales, fenómenos que constituyeron una forma de organización política de la sociedad en el territorio.

En general, los trabajos responden a un título según conceptos generales que luego se analizan con profundidad, y dentro de los cuales se distinguen subtítulos que clarifican y revisan la idea de paradigmas desde una base histórica y las transformaciones que tuvieron lugar hasta nuestros días. Además, al término de cada trabajo se observa una bibliografía muy completa que permite al lector un panorama general de las obras escritas sobre cada uno de los paradigmas analizados en cada apartado.

La obra resulta interesante, primero por la actualidad del tópico, dado que los cambios que se sucedieron, desde las conformación de sectores sociales, pasando por las actividad de la vida cotidiana y los transformaciones en el escenario de la vida urbana, en general permiten comprender un poco más sobre la revalorización y protección del legado cultural y el cómo fue conformándose el espacio urbano, territorio sobre el cual los actores sociales desarrollan sus relaciones y donde tienen lugar las actividades humanas. En segundo lugar, porque puede ser utilizado como modelo para llevar adelante estudios similares en otra región. 